2014

\title{
A Sampling of Popular Books for Numeracy Readers
}

\section{Michael T. Catalano}

Dakota Wesleyan University, micatala@dwu.edu

\section{Recommended Citation}

Catalano, Michael T.. "A Sampling of Popular Books for Numeracy Readers." Numeracy 7, Iss. 1 (2014): Article 7. DOI: http://dx.doi.org/10.5038/1936-4660.7.1.7 


\title{
A Sampling of Popular Books for Numeracy Readers
}

\author{
Abstract \\ Popular books on quantitative themes are seemingly more available than ever. In this book review, we \\ look at five such books from a wide range of authors. Although the books are written for diverse \\ audiences, all provide examples and discussion of concepts that could be used in courses with \\ quantitative literacy objectives. The books are Guesstimation and Guesstimation 2.0 by Lawrence \\ Weinstein and John A. Adam, and Weinstein, respectively; Turning Numbers into Knowledge: Mastering \\ the Art of Problem Solving, by Jonathan G. Koomey; How to Measure Anything: Finding The Value of \\ "Intangibles" in Business, by Douglas W. Hubbard; and Math on Trial by Leila Schneps and Coralie Colmez.

\section{Keywords} \\ Numeracy, Quantitative Literacy, Statistical Literacy, Problem solving, Critical thinking \\ Creative Commons License \\ (c) (i) (9) \\ This work is licensed under a Creative Commons Attribution-Noncommercial 4.0 License

\section{Cover Page Footnote} \\ Mike Catalano is the new Book Review Editor for this journal. He is a professor of mathematics and chair \\ of the department at Dakota Wesleyan University. He is a former member of the Board of Directors of \\ NNN and has a particular interest in incorporating numeracy into college algebra through the use of \\ examples related to social issues.
}




\section{Introduction}

The Book Reviews section has taken something of a hiatus from the pages of Numeracy, and so, to play a bit of catch up, this review will cover five books. The selection is primarily the result of my own interest in finding books that might provide examples for use in courses in quantitative literacy, college algebra, statistics, or other general education courses in mathematics. All five books are suitable for a general audience, although two authors have more specific audiences in mind and one in particular demands more sophistication and patience from the reader. I will consider each book in turn, and then close with some general comments.

\section{Turning Numbers into Knowledge}

We will proceed in chronological order, beginning with Turning Numbers into Knowledge: Mastering the Art of Problem Solving (Koomey 2008), the first edition of which was published in 2001. Jonathan G. Koomey is currently a Research Fellow at the Steyer-Taylor Center for Energy Policy and Finance at Stanford University. He has experience at the Lawrence Berkeley National Laboratory, the Energy and Resources Group at the University of California, Berkeley, and as editor for a journal on contemporary economic policy.

Koomey indicates that his book "grew out of [his] experience training analysts over the past two decades," and is targeted at students or professionals needing to do analysis in business, government, consulting, or research, or even journalists who will write about these areas. It is essentially a 'how to' book, advising readers on how to do analysis, how to critique the analysis of others, how to convince others your analysis is correct, and even how to use these skills to further your career. The book is, in fact, structured to be used as a textbook, including occasional exercises for the reader, albeit in a course for training analysts, not one in numeracy.

"Numeracy" is a term that is not particularly well-defined, and one might argue that neither is "problem solving." Koomey states in his preface that

problem solving takes more than proficiency with basic calculations: it requires understanding how people use information and learning about things as diverse as exploring your ideology, telling good stories, and distinguishing facts from values.

The preface continues with an annotated list of chapters which indicates that Koomey's notion of problem solving is quite broad, encompassing many facets of what I would call critical thinking. The chapter headings advise the reader to develop a "beginner's mind," to avoid being intimidated by authority, to be aware of your own ideological biases, to "distinguish facts from values," to develop mechanisms for "getting unstuck" in wrestling with difficult problems, and to "hear all sides" on any given issue. There is also what might be considered mundane advice on how to establish an efficient filing system, create quickly 
accessible compendiums of useful facts and figures, build a "toolbox" of helpful analytical tricks, avoid having your valuable time wasted, and learn to make accurate and thorough documentation a habit.

Despite the rather broad focus, Koomey does discuss topics that are more directly tied to notions of numeracy. For example, numbers that measure social or economic phenomena are likely to be less exact and reliable than numbers measuring physical phenomena. Koomey illustrates by debunking the notion, commonly held in the 1970s and 1980s, that energy use could not be reduced without negatively impacting gross domestic product, suggesting this notion resulted from ascribing to a historical relationship the same status as a physical law. He goes on to suggest that analysts of climate change are prone to falling into the same trap.

There is a chapter on "How Guesses Become Facts," covering several examples of how numbers, once published, can take on a life of their own. Exhibit A is a 1987 article by Koomey and Steve Greenberg which included some 'back of the envelope' roughly estimated ranges for electricity usage of small appliances like power tools or fish tanks in the U.S. Two years later, they found that the U.S. Department of Energy's Energy Information Administration had quoted their figures, sans the ranges and any indication of how rough these estimates were, in an official publication. This is definitely the type of example our college students should be advised to keep in mind, even if they complain about Koomey's antidote for this, which is to play detective and track down the original source of such numbers.

In Chapter 12, "Numbers Aren't Everything," Koomey disagrees with Douglas W. Hubbard, whose How to Measure Anything will be discussed below. Problem solvers should take into account that "not everything that matters can be quantified.” Readers of both books can form their own opinions regarding this philosophical question.

Koomey includes references to a number of other works that could be considered part of the numeracy literature, and these are conveyed both within the text and in a fairly comprehensive list of further readings, updated for the second edition. The classic How to Lie with Statistics, 1993, by Darrell Huff appears, and Edward Tufte's Visual Display of Quantitative Information and Envisioning Information are mentioned. Joel Best's Stat-spotting, reviewed in Numeracy by Joe Swingle (2009), is too recent to be in Koomey's list, but references to Best's older 2001 work Damned Lies and Statistics, Untangling Numbers from the Media, Politicians, and Activists is cited. One could certainly use Koomey's work as a starting point for further reading in numeracy and critical thinking in general, as well as discussions of information in the Internet age, and even leadership development (see Stephen Covey's The 7 Habits of Highly Effective People). 
Koomey's work is thorough and engaging. It is well illustrated with interesting examples, and has more than an adequate amount of humor. Calvin and Hobbes, Dilbert, and a host of other cartoon characters make appearances. Despite the stated target audience of current and future analysts, it is accessible to a general audience and certainly college students.

\section{How to Measure Anything}

As the title suggests, How to Measure Anything: Finding the Value of "Intangibles" in Business by Douglas W. Hubbard (2010, first edition 2007) has the ambitious agenda of convincing the reader that anything and everything can be measured quantitatively. Intangibles, in essence, do not exist. Certainly this claim is one that begs for discussion in a numeracy course, even if Hubbard's stated audience is decision makers and managers in the business world. Hubbard has had an extensive career in business consulting, and has developed a decision analysis method called Applied Information Economics. The book is in part a case for the value and applicability of this method, and some readers may find the episodes of self-promotion a bit off-putting. However, Hubbard does make his case thoroughly and energetically, and even those, like this reviewer, who find some of his claims overstated will, I think, benefit from engaging with Hubbard's text.

The book is organized into four sections which Hubbard indicates should be read in order. The first section sets out the thesis that anything (and he does mean anything) can be measured. This section includes a discussion of Eratosthenes' famous measurement of the size of the earth based on shadows in the Egyptian sands, as well as so-called "Fermi problems" that are the principal topic of the Guesstimation pair mentioned below. In Section Two, Hubbard argues that all significant measurement tasks should begin by first measuring the uncertainty, risk, and value of information in the given context. Section Three then provides some suggested methods for reducing uncertainty, and how to build on initial measurement efforts to improve subsequent ones. Section Four covers examples to illustrate the general methods already outlined.

Hubbard makes the case that even seemingly unquantifiable concepts such as a happy marriage can be numerically measured. A key part of making this case is to persuade the reader that any numerical information which reduces your uncertainty counts as a measure that has positive value, even if the measure is far from perfect. He challenges the reader to make a list of things believed to be either impossible or at least difficult to measure, and states his goal is to help you develop your own method to measure those things. Although he argues throughout that his methods have wide applicability, the initial outline of his proposal is given in the context of management decisions as follows:

1. "Management cares about measurements because measurements inform uncertain decisions."

2. "For any decision or set of decisions, there are a large combination of things to measure and ways to measure them - but perfect certainty is rarely a realistic option." 
3. "Therefore, management needs a method to analyze options for reducing uncertainty about decisions."

One simple method to reduce uncertainty is what Hubbard terms the "Rule of Five," which states that if you collect a random sample of five numerical data points from a given population, there is a $93.75 \%$ chance that the median of the population is between the smallest and largest values in your sample. The reasoning is simple. The chance that any one element of the sample is above the median is 50\%. Assuming independence, this means the chance that all five elements are above the median is $(0.5)^{5}$, or $3.125 \%$. There is the same chance all five elements of the sample are below the population median, and the result then follows. Now, if you had little or no idea what the median of the population under consideration might be before your small sample, you have reduced your uncertainty, and without a whole lot of work. I found this Rule of Five interesting in that it is both easily covered and potentially relevant in many numeracy contexts.

This example illustrates another one of Hubbard's larger points. Measurement methods do not necessarily have to be complicated and time consuming to be useful. A quick and dirty estimate might be sufficient in many situations. It seems to me that part of numeracy is being able to discern how much accuracy is "good enough" and that $100 \%$ confidence is never fully attainable.

One criticism that might be made of Hubbard's approach to measurement is that it leaves out other purposes for measurement. For example, measurement is sometimes used simply to confirm a result, or that a procedure is working as expected (e.g., quality control sampling). To me, it would be a stretch to characterize these situations as "reducing uncertainty about decisions." In fact, Hubbard describes one example where a bank for which he was consulting was producing numerous internal reports including all kinds of numerical measures that bank leaders admitted rarely had any effect on decision making. Does this necessarily mean that such measurements have no value?

Hubbard does go on to discuss at length what he calls the "value of information." This concept is based on both the cost of making the "wrong" decision, one that entails some amount of loss as compared to other choices, and the chance that you make the wrong decision. Hubbard argues for spending time measuring variables that have high information value, and ignoring or downplaying those with low information value. The discussion here gets more technical, including graphs that are essentially representations of Riemann sums, a bane of many first-year calculus students. However, the upshot is understandable even by less-sophisticated students of numeracy. A small amount of effort that produces a larger reduction in uncertainty is more worthwhile than a large amount of effort spent measuring a variable in which there is very little uncertainty.

Hubbard includes discussion of many topics that would be covered in undergraduate courses in statistics, including measures of central tendency, variance, confidence intervals, outliers, sampling techniques and survey design, how to avoid bias in sampling, and parametric statistics. Some of his explanations are more ad hoc and intuitive than "textbook." For example, Hubbard is critical of standard benchmarks for determining what counts as statistically significant. In his view, fixating on sample sizes often diverts attention from the more important goal of reducing uncertainty just enough to adequately inform a management decision. Instead of asking "how large should the sample be," he argues it is more important to focus on what is being measured and why. Especially if 
your current uncertainty is high, which is likely if you are trying to measure something you believed until recently was difficult or impossible to measure, you do not need a large sample to reduce uncertainty. Thus, those who like to go "by the book" may find Hubbard's attitude somewhat troubling at times, as well as his occasional reliance on personal experience and quotes from people in the "real-world" to trump standard statistical analysis protocols.

The book does include a fair amount of discussion that might be too detailed or not directly relevant to issues of numeracy per se. Still, Hubbard's advice to read cover to cover notwithstanding, those interested in numeracy can skip over parts of the book and still find a lot that would be useful in teaching quantitative literacy, particularly if you have a lot of business students in your course. It is fair to say that of the five books in this review, Hubbard's makes the greatest demands on the reader.

\section{Guesstimation and Guesstimation 2.0}

Of the works covered in this review, Guesstimation (Weinstein and Adam 2008) and Guesstimation 2.0 (Weinstein 2012) have the narrowest focus, but they cover that focus quite thoroughly. As a set, they form a sort of compendium of estimation examples, categorized by topic. The charm of the two is that you can find examples related to almost any issue, from energy to the environment, politics to porta-potties, physics to phone usage. The downside is that the flavor of the problems is all the same. For those familiar with "Fermi problems," here they are in abundance.

Both volumes open with a chapter on how to solve problems, but 'problem' here really means nothing more than finding an answer to an estimation question. Certainly Weinstein and Adam's definition of problem solving is much more limited than Koomey's described above. Estimation is seen as a means to the end of making decisions, not unlike what Hubbard argues for. Should I install a solar panel on my house? Should we be growing corn for ethanol? Paper or plastic? In solving the given problem, the reader is advised not to be more precise than the assumptions allow or that the particular decision requires. Often, simply getting within one order of magnitude is sufficient. This is certainly a theme relevant to those interested in numeracy, and students can gain something by considering the authors' discussion of how precise estimates need to be to have usefulness. It is a more informal version of the similar discussion found in Hubbard. The chapter includes a procedure for breaking down the problem into pieces, providing bounds or estimates on each 'piece,' and then multiplying or dividing the estimates for each piece as appropriate. "How much area could we cover with all the pizza boxes used by Americans in one year?" is the first example used to illustrate the process in Guesstimation 2.0. This is broken down into estimating the population of the U.S., the number of pizzas eaten by each American in a year, and the area of a pizza in square meters.

While many of the examples concern issues of global import, there are many, like the pizza box example, which will strike some readers as trivial pursuit, especially after several chapters of reading. "How far does a car travel before a one-molecule layer of rubber is worn off the tires?" and "How much waste is generated per kilometer by a horse-drawn carriage?" are two more. Of course, there is no need to read these books 
cover to cover or in order, so readers can focus in on the examples they find interesting, digesting them in small chunks if desired.

The appendices include some general numerical benchmarks useful in estimation problems, like the populations of the world and the U.S., physical constants like the size of an atom, the energy in a calorie, the strength of gravity, formulas for potential energy and work energy, distances from the subatomic to the astronomical. They are listed in several tables organized by orders of magnitude, a useful scheme for giving students a sense of scale. The authors do tend to prefer the metric to the English system of measures, and, at times, they jump back and forth quickly between the two. A reader would be well advised to nail down some of the common conversions between these systems in their own mind at the outset to avoid confusion as one proceeds. How many readers will know that 1000 square kilometers is roughly the same as 500 square miles and that this is the area of a large city?

For the general reader, the books can be entertaining and informative, if occasionally a tough slog for the less numerate. For a college or even a high school instructor, they can serve as a source of interesting examples for classroom use or exercises. The writing style is informal and, to me, fairly engaging, with a number of tongue-in-cheek moments. For example, the second chapter of 2.0 begins with a comment about using estimation techniques to solve some of life's important problems. A discussion of the length of all the toilet paper used in the U.S. in a year and the amount of literature a large number of monkeys might put out follows.

Koomey has a small dose of the Guesstimation paradigm in his Chapter 29, entitled "Reuse Old Envelopes." Here you will find the same breaking down of the problem into its component parts, tracking of units, etc. An exercise on estimating the number of cobblers in the U.S. is included.

To close this section, for those who are interested, it would take about four times as much land area to grow corn sufficient to provide for U.S. food and energy needs as it does to provide for food alone.

\section{Math on Trial}

Of the five books in this review, Math on Trial: How Numbers Get Used and Abused in the Courtroom (Schneps and Comez 2013) proved the hardest for me to put down. The authors have chosen a set of ten interesting trials, several of them quite famous, and presented them in engaging and informative prose. Each chapter focuses on a given legal case, and each case is matched with a "math error." Chronologically, the cases range from an 1860s suit involving Hetty Green, whose wealth at one point rivaled that of the Rockefellers and the Morgans, and the allegedly forged will of her husband, to the gruesome and still unfolding Amanda Knox drama.

Several of the math errors will be familiar to students of numeracy, but a few are designated in the chapter headings with somewhat vague or nonstandard terms. The last chapter, for example, covers the infamous Dreyfus Affair which is said to illustrate "mathematical madness." This is explained by the example of being amazed that your friend hit the bulls-eye five times in a row without taking into account the number of off- 
the-mark attempts which preceded that event. There are cases covering Simpson's Paradox, the birthday problem, the error of multiplying non-independent probabilities, and confusion in analyzing "incredible coincidences." The chapter on the Amanda Knox case, named in the book for the victim Meredith Kercher, lists "Double Experiment" as the math error. The crux of the issue in that case was a judge not understanding the validity of multiplying probabilities that can be reasonably assumed to be independent, and assuming, rather, that a second experiment cannot provide any additional information.

The error of underestimation is represented by the case of Charles Ponzi, with reference to the more-recent case of Bernie Madoff. The obvious issue here is how so many individuals with money could fail to see that exponential growth at the rate of $100 \%$ every three months is simply not sustainable in reality. Arguably, the problem here is not so much mathematical as psychological. People often simply choose to believe (or not believe) certain information, quantitative or otherwise, based on the consequences of that belief. On the other hand, our psychological reactions to numbers are legitimately a part of numeracy, and those of us who endeavor to teach students quantitative literacy are (or should be) well aware of this issue.

Perhaps the most poignant case is that of Lucia de Berk, a nurse in the Netherlands who was convicted of multiple murders of infants based on a faulty probability analysis of deaths which, in retrospect and many years later, were seen to be coincidences easily within the realm of possibility. Multiple appeals were made to no avail, and the proceedings resulted in ongoing and severe public vilification of de Berk. She eventually suffered a stroke in prison which, due to prison authorities' believing her symptoms were faked, was not treated in a timely manner and led to de Berk losing her power of speech and motion on the right side of her body. Seven years after her original conviction, de Berk was finally exonerated.

The book is certainly accessible to the general audience, and I think students of quantitative literacy will find many of the examples interesting, engaging, and instructive. It certainly gets across the point that easily understandable math errors can be made by professionals who should know better and can have significant consequences.

\section{Concluding Comments}

None of these five books were specifically written for use in a numeracy course. However, I think they are worth reading by those who are interested in numeracy and critical thinking, even if only for the alternative perspectives they provide. Numeracy can be considered a set of skills, but also can be defined to include dispositions that incline individuals to use those skills, and to have confidence in their ability to do so. Numeracy does not exist in isolation, but can be thought of as part of a larger set of critical thinking skills. Thus, even books that are not exclusively devoted to the nuts and bolts of numeracy skills can have value in promoting those skills.

The Guesstimation series and Math on Trial would be the simplest of these five books to incorporate into a course specifically focused on numeracy. One could easily pick and choose individual chapters or sections to go along with topics being covered in the classroom. These three volumes are both affordable and accessible, both compared to 
the other two books reviewed here and even books like Best's Stat-Spotting. For some types of courses, almost any individual section in Guesstimation could serve as a source for a homework problem or in-class group activity. An instructor could ask students to investigate the value of various kinds of recycling (chapter 3 in 2.0), or find the amount or cost of the energy required to transport a ton of cargo across the U.S. by plane (section 6.6 in the same). Students could either read the solution themselves out of the book, or they could work on it independently and discuss their various solutions later in class. One could also assign sections or chapters for individual reading, or perhaps as the grist for student presentations.

One topic from Math on Trial that I incorporated into a course this year is Simpson's Paradox. Students often have difficulty appreciating the effect of group sizes when considering averages. For example, the average of the per capita incomes for the 50 states will not be the same as the per capita income for the whole country because of the population differences between the states. Simpson's Paradox occurs when averages calculated for a number of groups all increase from one point in time to another, but the average for all individuals from these various groups considered as a single group does not. An example, cited in Math on Trial, is shown in Table 1.

Table 1

Example of Simpson's Paradox from Math on Trial

\begin{tabular}{cccccccc}
\hline & & \multicolumn{6}{c}{ SAT Verbal Scores } \\
Year & White & Black & Asian & Mexican & $\begin{array}{c}\text { Puerto } \\
\text { Rican }\end{array}$ & $\begin{array}{c}\text { American } \\
\text { Indian }\end{array}$ & Total \\
\hline 1981 & 519 & 412 & 474 & 438 & 437 & 471 & 504 \\
2002 & 527 & 431 & 501 & 446 & 455 & 504 & 504 \\
\hline
\end{tabular}

The data in Table 1 show that SAT Verbal Scores increased for every single ethnic group used as of 1981, and yet the overall score for all students remained unchanged. Most students will be perplexed as to how this is possible. The issue is that over this 21year period from 1981 to 2002, the proportion of students in the highest scoring group, whites, decreased, and the proportion of students in several of the other lower scoring groups, particularly Blacks and Mexicans, increased.

Whether these data have been featured in any trials related to Affirmative Action I am not sure, but Schneps and Colmez do include the case of one Jenny Harrison in their book. Table 2 shows a homework problem I assigned in my college algebra classes this semester (Fall 2013) based on their discussion, and the data given are also provided in Math on Trial. A short discussion of Simpon's Paradox is included in the chapter where this problem appears, so students do have some background on the paradox before beginning work on the problem. One can certainly base other sets of questions on the same data as are in Table 2. With respect to Harrison's tenure case, after her original rejection in 1986, she and Berkeley reached a settlement in 1993 providing her with a tenured position as well as an undisclosed amount of compensation. In the meantime, the university also found out why female admissions were so low; women tended to apply to programs that were more difficult to get into, and this was possibly due to wider cultural biases affecting their choices. 
Most of the other chapters in Math on Trial could be condensed into problems or activities. None of the mathematics involved is overly difficult, and trials bring a drama of their own that students often find compelling.

Table 2

Homework Exercise Inspired by Example in Math On Trial

In the 1980's, Berkeley University was sued by Jenny Harrison, an assistant professor of mathematics, for sex discrimination after her initial application for tenure was denied. As part of the resulting investigation, the University collected data on graduate school admissions by gender and found that six of the larger departments collectively approved $46 \%$ of male applicants, but only $30 \%$ of female applicants

(a) Explain why the fact that $46 \%$ of male applicants are approved, while only $30 \%$ of female applicants are approved does not necessarily indicate gender bias on the part of these six departments. What relevant information is not being included here?

(b) The table below shows the actual numbers and percentages for each of the six departments (one of which is mathematics, but these are being kept anonymous). Do these data support or refute claims of gender bias? Explain.

(c) Why is the overall percentage of women admitted lower than the percentage of men?

\begin{tabular}{|ccccccc|}
\hline Data for this exercise: & $\begin{array}{c}\text { Number of } \\
\text { Male } \\
\text { Applicants }\end{array}$ & $\begin{array}{c}\text { Number of } \\
\text { Male } \\
\text { Admissions }\end{array}$ & $\begin{array}{c}\text { Number of } \\
\text { Female } \\
\text { Applicants }\end{array}$ & $\begin{array}{c}\text { Number of } \\
\text { Female } \\
\text { Admissions }\end{array}$ & $\begin{array}{c}\text { Percentage } \\
\text { of Male } \\
\text { Admissions }\end{array}$ & $\begin{array}{c}\text { Percentage } \\
\text { of Female } \\
\text { Admissions }\end{array}$ \\
\hline A & 825 & 511 & 108 & 89 & 62 & 82 \\
B & 560 & 353 & 25 & 17 & 63 & 68 \\
C & 325 & 120 & 593 & 202 & 37 & 34 \\
D & 417 & 139 & 375 & 131 & 33 & 24 \\
E & 191 & 53 & 393 & 94 & 6 & 7 \\
F & 272 & 16 & 341 & 24 & 6 \\
\hline
\end{tabular}

Koomey and Hubbard are less suited for direct use in a numeracy course, given their more-specialized audiences and, especially in Hubbard's case, somewhat denser presentation. Still, there are examples one could modify to use in a classroom setting, or the books could serve simply as sources for alternative ways to think about or present concepts related to numeracy and critical thinking. For example, both of these books include stories designed to show the relevance of the material to their target audiences. Hubbard narrates how, in the 1970s, the EPA used the crude technique of observing (via binoculars) motorists gassing up to estimate what percentage of cars were using leaded gasoline in newer vehicles designed to run on unleaded gas. The estimate they made, about $8 \%$ of motorists were flouting the rules, was sufficient to allay concerns that the existence of the rules was actually making air pollution worse, since the newer cars using the older gas produced more pollution than the older cars using the older gas. Now, perhaps stories of this sort could be considered fluff. However, it seems to me that persuading students that numeracy skills are relevant and even interesting is a worthy goal, and perhaps one many of us give short shrift to. Stories that students can identify with can help accomplish that goal.

In a chapter on the perils of bad data, Koomey relates how neglecting to convert English to metric in one key data file led to the Mars Climate Orbiter being lost in space. The U.S. ended up spending \$125 million for a failed project. The lesson is to check your data for errors. The chapter in which this example appears goes on to give specific advice for avoiding errors due to bad data, all of which is appropriate and useful for 
students in a numeracy course. Items of advice include cross-checking main totals and subtotals of data you acquired from another source yourself, checking the vintage of the data (what year were they collected), comparing data values to appropriate benchmarks for reasonableness, and normalizing data to more intuitive units. An example of the latter would be to convert Gross National Product totals, which are typically in the billions or trillions of dollars, to GNP per person, a number more directly understandable.

In fact, Koomey's introduction is a quick, interesting, and relevant read all by itself. The theme is the explosion of knowledge in the Internet age. The stated goal presented for the book is to help readers steer between the response of trying to digest everything the Internet has to say, and ignoring everything it has to say. It is certainly a lesson we can all benefit from.

Even if one never uses a particular example from any of these books in class, I think engaging with these works is a beneficial exercise for anyone teaching numeracy courses or numeracy skills in the context of other courses.

\section{References}

Best Joel. 2008. Stat-spotting: Field guide to identifying dubious data. Berkeley, CA: University of California Press.

Hubbard, Douglas W. 2010. How to measure anything: Finding the value of “intangibles" in business. Hoboken, NJ: Wiley.

Koomey, Jonathan G. 2008. Turning numbers into knowledge: Mastering the art of problem solving, 2nd ed. Oakland, CA: Analytics Press.

Miller, Andrew. 2011. Four popular books on consumer debt: A context for quantitative literacy." Numeracy 4 (1): Article 7. http://dx.doi.org/10.5038/1936-4660.4.1.7 (accessed Nov. 30, 2013).

Schneps, Leila and Coralie Colmez. 2013. Math on trial: How numbers get used and abused in the courtroom. New York: Basic Books.

Swingle, Joe. 2009. "Review of Stat-spotting: A field guide to identifying dubious data by Joel Best. Numeracy: 2 (2): Article 7. http://dx.doi.org/10.5038/1936-4660.2.2.7 (accessed Nov. 30, 2013).

Weinstein, Lawrence. 2012. Guesstimation, 2.0, Solving today's problems on the back of a napkin. Princeton, NJ: Princeton University Press. , and John A. Adam. 2008. Guesstimation: Solving the world's problems on the back of a cocktail napkin. Princeton, NJ: Princeton University Press. 